\title{
A Randomized Double-Blind, Placebo-Controlled Trial of Minocycline in Children and Adolescents with Fragile X Syndrome
}

\author{
Mary Jacena S. Leigh, MD(1),(2), Danh V. Nguyen, $\mathbf{P h D}^{(3)}$, Yi Mu, MS ${ }^{(3)}$, Tri I. Winarni, MD(4), \\ Andrea Schneider, PhD(1),(2), Tasleem Chechi, BS ${ }^{(1),(2)}$, Jonathan Polussa, BS ${ }^{(1),(2)}$, Paul \\ Doucet, BA ${ }^{(2)}$, Flora Tassone, PhD(2),(5), Susan M. Rivera, PhD(2),(6), David HessI, PhD(2),(7), \\ and Randi J. Hagerman, MD(1),(2) \\ (1)Pediatrics, University of California Davis Medical Center, Sacramento, CA, United States of \\ America \\ (2)MIND Institute, University of California Davis, Sacramento, CA, United States of America \\ (3)Biostatistics, University of California Davis, Davis, CA, United States of America \\ (4)Human Genetics, CEBIOR Diponegoro University, Semarang, Central Java, Indonesia \\ (5)Biochemistry and Molecular Medicine, University of California Davis, Sacramento, CA, United \\ States of America \\ (6)Psychology, Center for Mind and Brain, University of California Davis, Davis, CA, United States \\ of America \\ (7)Psychiatry and Behavioral Sciences, University of California Davis, Sacramento, CA, United \\ States of America
}

\section{Abstract}

Objective-Minocycline rescued synaptic abnormalities and improved behavior in the fragile $\mathrm{X}$ mouse model. Prior open-label human studies demonstrated benefits in individuals with fragile $\mathrm{X}$ syndrome (FXS); however, its efficacy in patients with FXS has not been assessed in a controlled trial.

Method-Randomized, double-blind, placebo-controlled, crossover trial in individuals with FXS, ages 3.5-16 years ( $\mathrm{n}=55$, mean age 9.2 (SD 3.6 years)). Participants were randomized to minocycline or placebo for three months, then switched to the other treatment.

Results-Sixty-nine subjects were screened and 66 were randomized. Fifty-five subjects (83.3\%) completed at least the first period and 48 (72.7\%) completed the full trial. Intention-totreat analysis demonstrated significantly greater improvements in one primary outcome, Clinical

The corresponding author is: Mary Jacena Leigh MD Developmental and Behavioral Pediatrics University of California MIND Institute $282550^{\text {th }}$ Street Sacramento CA 95817 Phone: 916-703-0261 Fax: 916-703-0243 maryjacena.leigh@ ucdmc.ucdavis.edu.

Conflicts of Interest: Dr. Hagerman has received funding from Hoffman LaRoche, Novartis, Seaside Therapeutics, Forest and Curemark for treatment trials in patients with FXS, autism and fragile X-associated tremor ataxia syndrome (FXTAS). She is also on the Treatment Advisory Board for Novartis regarding FXS treatment studies. Dr. Hessl has received financial support from Hoffman LaRoche, Novartis, and Seaside Therapeutics for clinical trials of patients with fragile X syndrome. The other authors report no financial interests or conflicts of interest.

This is a PDF file of an unedited manuscript that has been accepted for publication. As a service to our customers we are providing this early version of the manuscript. The manuscript will undergo copyediting, typesetting, and review of the resulting proof before it is published in its final citable form. Please note that during the production process errors may be discovered which could affect the content, and all legal disclaimers that apply to the journal pertain. 
Global Impression Scale-Improvement after minocycline compared to placebo $(2.49 \pm 0.13,2.97$ \pm 0.13 , respectively, p 0.0173) and greater improvement in ad hoc analysis of anxiety and moodrelated behaviors on the Visual Analoge Scale (minocycline $5.26 \mathrm{~cm} \pm 0.46 \mathrm{~cm}$, placebo $4.05 \mathrm{~cm}$ $\pm 0.46 \mathrm{~cm} ; \mathrm{p} 0.0488$ ). Side effects were not significantly different during the minocycline and placebo treatments. No serious adverse events occurred on minocycline. Results may be potentially biased by study design weaknesses, including unblinding of subjects when they completed the study, drug-related side effects unblinding and preliminary efficacy analysis results known to investigators.

Conclusion-Minocycline treatment for three months in children with FXS resulted in greater global improvement than placebo. Treatment for three months appears safe; however, longer trials are indicated to further assess benefits, side effects, and factors associated with a clinical response to minocycline.

\section{Keywords}

Fragile X Syndrome; Intellectual Disability; Minocycline; Matrix Metalloproteinase 9

\section{INTRODUCTION}

Fragile X syndrome (FXS) is the most common inherited cause of intellectual disability and the most common single gene cause of autism. Prevalence estimates are 1 in $~ 4000-8000$, however, the full mutation allele frequency may be as high as 1 in $~ 2500$ in some populations ${ }^{1,2}$. The phenotype associated with FXS includes both behavioral and cognitive deficits in addition to physical features, such as prominent ears, hyperextensible finger joints and macroorchidism, which begins at puberty. The behavioral phenotype typically includes attention deficit hyperactivity disorder (ADHD), anxiety and intermittent aggression, which can cause significant difficulties for the families.

FXS is almost always caused by a CGG repeat expansion in the $5^{\prime}$ region of the FMR1 gene on the X chromosome. Greater than 200 CGG repeats confer the full mutation, leading to silencing of the gene and a deficit of the gene's product, fragile $\mathrm{X}$ mental retardation protein (FMRP). FMRP is a key regulator of translation of many mRNAs into their specific proteins, so the deficiency of FMRP leads to up-regulation of many proteins important for synaptic plasticity ${ }^{3-5}$.

The lack of FMRP in individuals with FXS leads to up-regulation of downstream components of the metabotropic glutamate receptor 5 (mGluR5) pathways ${ }^{6}$. For further discussion of this, please see Dolan et al $2010^{7}$. The mGluR5 negative modulators represent the first targeted treatment for FXS and have been found to be helpful in animal models of $\mathrm{FXS}^{8}$. In individuals with FXS, mGluR5 antagonists, including fenobam and AFQ056, have shown preliminary evidence of efficacy in initial studies 9,10 . Lithium is also a targeted treatment for fragile $\mathrm{X}$ syndrome as it decreases mGluR5 activated translation and was found to be efficacious in an open label trial in individuals with FXS. ${ }^{11}$ Another potential pathway which may be targeted in the treatment of FXS is the gamma-aminobutyric acid (GABA) system, which is down regulated in FXS and in a recent randomized controlled phase II trial, treatment with arbaclofen, a gamma-aminobutyric acid type B (GABA(B)) agonist, led to improvements in social avoidance and behavior in individuals with FXS, but is not yet available for prescription. ${ }^{12}$

The lack of FMRP in individuals with FXS is also associated with alterations in the expression of a number of proteins, including matrix metalloproteinase 9 (MMP9). ${ }^{13}$ Matrix metalloproteinases are endopeptidases (please see Sternlicht and Werb 2001 for further discussion of their role in the cell) ${ }^{14}$ and MMP9 has been found to be fundamental in 
modulating hippocampal synaptic physiology and plasticity ${ }^{15}$. In the Fmr1 knock out (KO) mouse model for FXS, MMP9 levels were found to be elevated in the hippocampus and lowered by minocycline treatment ${ }^{13}$. Minocycline is a semisynthetic tetracycline derivative that has been available since the 1970s and its potential as a neuroprotective agent was first investigated by Yrjanheikki and colleagues as a possible treatment for cerebral ischemia ${ }^{16}$. Bilousova and colleagues found that early treatment with minocycline ( $<4$ weeks) after birth led to maturation of the immature dendritic spines found in the Fmr $1 \mathrm{KO}$ mice, suggesting that dendritic maturation may be related to minocycline's lowering of MMP9.

Improvements in anxiety and cognition were also seen in the treated mice ${ }^{13}$. In the Drosophila model of FXS, over-expression of the only tissue inhibitor of MMPs, Tissue Inhibitor of Metalloproteinase (TIMP), prevented the synaptic defects seen in the dfmr1 mutants and minocycline treatment was found to normalize synaptic structure ${ }^{17}$. Minocycline treatment was also found to normalize ultrasonic vocalizations of Fmr1 KO mice during mating ${ }^{18}$.

Minocycline is a common treatment for multiple conditions including acne vulgaris and infectious diseases such as Rocky Mountain Spotted Fever, but has also been found to have neuroprotective effects ${ }^{19}$. It has a well-defined side effect profile including gastrointestinal problems ranging from stomach upset to the rare possibility of pseudomembranous colitis, tooth and oral cavity discoloration, a lupus-like syndrome, increased photosensitivity, pseudotumor cerebri, and autoimmune hepatitis ${ }^{20}$. Due to the possibility of graying of the permanent teeth, minocycline is generally not recommended in children younger than 8 years of age, (as mineralization of the teeth is not complete until after that age), unless there are no other medications that are likely to be effective.

The benefits of minocycline demonstrated in the KO mouse model prompted studies to investigate the effects of minocycline in individuals with FXS. Utari and colleagues (2010) reported a survey of caregivers of children and adults with FXS who were treated with minocycline clinically for at least 2 weeks. Side effects were seen in $39.6 \%$ and caregivers reported improvements in language, attention, social communication, and/or anxiety in approximately $70 \%{ }^{21}$. Paribello and colleagues (2010) conducted an open-label add-on trial of minocycline in individuals with FXS 13-32 years of age. Minocycline treatment, well tolerated in this study, was associated with improvements in behavior ${ }^{22}$. The results of these studies have stimulated a larger randomized, double-blind study reported here.

\section{Objective/ Hypothesis}

Our objectives in this study were to determine the behavioral effects of minocycline through a randomized, double-blind, placebo-controlled crossover trial. Side effects were closely monitored to assess the tolerability of minocycline treatment. Our hypothesis was that minocycline reduces problematic behaviors and that it is safe for use in children with FXS ages 3.5-16 years of age for three months. We sought to examine the role of age, gender, methylation status, concomitant medication use, full scale IQ and severity of autistic behaviors on the effects of minocycline in children with FXS.

\section{METHODS}

\section{Study Design and Patients}

This was a 6-month, single center, placebo-controlled, double-blind crossover trial of minocycline treatment. Participants received 3 months of treatment with minocycline and 3 months of treatment with placebo. There was no washout between the two treatment periods. Recruitment occurred from January 2010 to June 2011, with the last participants completing the study in December 2011. Results were disclosed at the end of the trial for each patient. 
Patients were recruited through the University of California Davis (UC Davis) Medical Investigation of Neurodevelopmental Disorders (MIND) Institute's Fragile X Research and Treatment Center and through the National Institute of Health's ClinicalTrials.gov registry.

Inclusion criteria included a diagnosis of FXS confirmed by FMR1 DNA testing, age between 3.5-16 years and a stable regimen of pharmacological treatment for at least 4 weeks prior to study entry. Both male and female individuals were included. Exclusion criteria included those who were previously treated with minocycline, plan to change pharmacological intervention during the study or had an allergy to minocycline or tetracycline. There were no exclusions for concomitant medication use.

Informed consent was obtained from caregivers prior to participation and an assent was also obtained from patients aged 12 years or older. Due to our vulnerable subject population's cognitive impairment, signatures were not always obtained on the assent, but patients were verbally briefed on the study description. The study was approved by the UC Davis Institutional Review Board.

\section{Randomization}

Potential participants were assessed initially by telephone with a screening questionnaire for inclusion and exclusion criteria. Participants who met eligibility criteria were scheduled for a baseline visit. After clinicians determined a participant was eligible, randomization was done by the UC Davis Medical Center Investigational Drug Service based on order of receipt of study medication prescription. The random allocation sequence to 3 months of minocycline or placebo first was generated via an online randomization program. No block randomization was done. All study personnel, investigators, and participants were blinded to treatment assigned until completion of the trial period.

\section{Intervention}

Study medication consisted of identical appearing capsules. The placebo contained the same inactive ingredient as the minocycline capsules, methylcellulose. Medication dosage was assigned based on weight, with patients weighing up to $25 \mathrm{~kg}$ receiving $25 \mathrm{mg}$ once daily, those weighing between 25 and $45 \mathrm{~kg}$ receiving $50 \mathrm{mg}$ once daily, and those weighing $>45$ $\mathrm{kg}$ receiving $100 \mathrm{mg}$ once daily. Patients were advised to avoid dairy products at least 30 minutes before and after taking study medication due to the possibility of minocycline chelating with calcium, thus decreasing absorption. Participants who were not able to swallow the capsules were allowed to mix the capsule contents with non-dairy food. After patients were treated for 3 months with either minocycline or placebo, they were crossed over and treated for the following 3 months with the alternate therapy.

\section{Assessments, Follow-up and Dose Monitoring}

At baseline before the first treatment period, each patient underwent standardized cognitive testing as appropriate for age and expressive language level. Testing was administered by a licensed psychologist or psychometrist with experience testing individuals with FXS. Measures used were the Stanford Binet $5^{\text {th }}$ Edition ${ }^{23}$, Wechsler Abbreviated Scale for Intelligence (WASI) ${ }^{24}$, Mullen Scales of Early Learning ${ }^{25}$ or the Leiter-Revised ${ }^{26}$. An Autism Diagnostic Observation Schedule (ADOS) and Diagnostic and Statistical Manual of Mental Disorders, Text Revision IV (DSM-IV) diagnostic criteria were used to evaluate participants for an autism spectrum disorder (ASD), which was determined by clinician consensus.

At all visits, patients had a medical evaluation which included a detailed medical history, therapeutic intervention review, medication review, side effects checklist and physical exam. 
The physicians discussed potential side effects with caregivers and patients including but not limited to the possibility of discoloration of the teeth, particularly in those younger than 8 years of age, gastrointestinal problems, increased sun sensitivity, idiopathic intracranial hypertension and a drug induced lupus-like reaction.

Primary and secondary outcome measures were performed at baseline, repeated after 3 months at the end of the patients' first treatment arm and then at 6 months after the second arm. The primary outcome measures were the Clinical Global Impressions ScaleImprovement (CGI-I) and the Visual Analogue Scale (VAS) for severity of target behaviors for the most significant symptoms that caregivers wanted to see improve (VAS1, severity of target behavior 1). The CGI-I utilizes history from primary caregivers and incorporates it into a seven step clinical rating for follow up throughout treatment, from 1 "very much improved" to 7 "very much worse". A VAS is used to represent a caregiver's assessment of given behaviors, which were chosen by the parents. Caregivers marked a $10 \mathrm{~cm}$ horizontal line representing a visual continuum of each behavior from "worst behavior" to "behavior not a problem." Visual analogue scales have been used in multiple prior studies to evaluate conditions such as anxiety, depression and quality of life ${ }^{27-29}$.

Secondary outcome measures were the Visual Analogue Scale for severity of target symptoms rated second and third by the parents (VAS 2 and VAS3, severity of target behavior 2 and 3, respectively), Aberrant Behavior Checklist Community Edition (ABC-C) composite score and subscales as well as subscales that have been validated for the FXS population, the Expressive Vocabulary Test Second Edition (EVT-2), and Vineland Adaptive Behavior Scale-II (VABS-II). The original and revised versions of the ABC-C were used to quantify the severity of a patient's behaviors ${ }^{30,31}$. The EVT-2 assesses language development through a participant's one word synonym response to visual stimuli ${ }^{32}$. The VABS-II was used to assess adaptive skills ${ }^{33}$.

Along with participants being followed with clinic visits every 3 months for up to 6 months, phone calls took place throughout the study (on days 7, 30, 60, 120, 150 and 180) to review concomitant medications and list of questions regarding common side effects seen with minocycline.

\section{Molecular Measures}

A blood sample for FMR1 molecular measures, including CGG repeat size, and methylation status was obtained from each participant or results were provided by caregivers. Southern Blot and PCR-based genotyping were performed as previously described ${ }^{34}$

\section{Statistical Analysis}

The model to assess efficacy was a linear mixed-effect (LME) model for repeated measures in a minocycline/placebo, two-period cross-over trial. The model terms included treatment, period, and baseline measurement if available. Estimation was based on restricted maximum likelihood and test denominator degrees of freedom was based on the Kenward-Roger approximation. A model including the sequence factor was used to check for a carryover effect. Analysis of secondary measures follows the same approach. In ad hoc analysis, the LME models include baseline covariates to examine their effects, including concomitant medication use, methylation status (full or partial), full scale IQ score, and ADOS total score, gender and age group ( $<8$ or $\geq 8$ years of age). In ad hoc analysis (not planned $a$ priori) of symptom or behaviors described in the 3 VAS symptoms provided by caregivers, we categorized the symptoms into anxiety/mood symptoms, language-related symptoms, ADHD/impulsive symptoms or other category. For example, for anxiety/mood, we defined a combined symptom-specific VAS score as the average of the individual VAS scores for 
those specific behaviors/symptoms. Similarly, combined VAS scores for language-related symptoms, ADHD/impulsive symptoms or other category were determined. Comparison of baseline and demographic variables between treatment sequences were based on the t-test and Fisher's exact test for continuous and categorical variables, respectively. Adverse events were summarized by type and severity and compared using the generalized equation estimation approach and conclusions were the same based on Fisher's exact test. All tests were at level 0.05 and analyses were implemented in SAS version 9.2.

The study was designed to achieve $85 \%$ power to detect a treatment effect size of 0.55 at level alpha $=0.025$ in a crossover design. The required sample size is 74 but funding limitations limited the number to 66 who were randomized.

\section{RESULTS \\ Demographics}

Sixty-nine subjects were assessed for eligibility, 66 of which were randomized into the two treatment arms (Figure 1). Fifty-five subjects (83.3\%) completed at least the first period and were included in the intention-to-treat analysis. The demographic characteristics of these fifty-five subjects are shown in Table 1. There was no significant difference between the two treatment sequences (minocycline-placebo or placebo-minocycline) for baseline and demographic variables. Forty-eight $(72.7 \%)$ subjects completed the second period. The majority of subjects in both treatment sequences were boys, race white and average age of 9.0 years (minocycline-placebo) and 9.4 years (placebo-minocycline).

\section{Primary Outcome Measures}

The primary outcome measures are CGI-improvement and VAS1 score (severity of target behavior 1). Minocycline showed statistically significant improvement in CGI-I (2.49 \pm 0.13$)$ compared to placebo $(2.97 \pm 0.13$, p 0.0173); however, there was no difference between treatment groups with respect to VAS1 (p 0.67). See Table 2 (items 1 and 2a),Although statistically significant, the CGI-I improvement (average of 0.5 points) was modest. The average VAS scores were rated as more improved on minocycline than placebo, but the difference was not significant. The largest improvement trend was for the VAS2 score (severity for target behavior 2) (minocycline $4.91 \mathrm{~cm} \pm 0.31 \mathrm{~cm}$, placebo $4.16 \mathrm{~cm} \pm 0.29 \mathrm{~cm} ; \mathrm{p}$ $0.0607)$, a secondary measure.

\section{Ad Hoc Analysis of VAS by Behavior Category}

We performed an ad hoc analysis (not planned a priori) of VAS scores 1-3 by behavior category, as detailed in the 'Statistical Analysis' section; see Table 1 - item 2b. When the VAS behaviors were grouped by behavior category, minocycline was associated with a significantly greater improvement in anxiety and mood related behaviors (minocycline 5.26 $\mathrm{cm} \pm 0.46 \mathrm{~cm}$, placebo $4.05 \mathrm{~cm} \pm 0.46 \mathrm{~cm} ; \mathrm{p} 0.0488$ ). Greater improvement was observed also for the "other" category, which included being organized, potty training, self-calming/self soothing, verbal initiation for play, chewing objects, overstuffing, scratching stomach, belching, running away, non-compliance/defiance, and self injury. No significant carry over effects were observed from the first treatment period to the next.

\section{Secondary Outcome Measures}

We did not observe any significant treatment effect with respect to secondary measures which included the ABC-C, fragile X specific ABC-C, VABS-II, EVT2, VAS2 and VAS3 


\section{Baseline Variable Effects}

Additional ad hoc analyses explored effects of baseline variables. Baseline concomitant medication use, methylation status (full or partial), full-scale IQ score, and ADOS total score were not significant in models of treatment differences. Covariates gender and age group ( $<8$ or $\geq 8$ years of age) were significant in models for VAS target behavior 2 only, and trends of treatment effects reported for primary analysis above were similar ( $\mathrm{p}=0.0345$ and 0.0458 , respectively).

\section{Safety and Tolerability of Minocycline}

There were 144 adverse events (AEs) reported for 54 subjects (81.8\%). Table 3 summarizes the types of AEs. The majority of adverse events were rated as mild (94.4\%). There was no significant difference between minocycline and placebo with regard to intensity, relationship to study medication, resolution, and categories of adverse events. The most common adverse events noted were gastrointestinal symptoms including loose stools and decrease in appetite. There was one adverse event rated as "serious" which was a seizure and when the patient was unblinded, this occurred during the placebo arm. Most side effects resolved. Of note, brown and yellow tooth discolorations were reported during the minocycline trial period for 5 patients. However, most of these discolorations resolved, and their significance is unclear as the tooth staining associated with tetracyclines is typically permanent.

\section{DISCUSSION}

This study is the first double-blind crossover study of minocycline as a targeted treatment in FXS. Prior open label studies have shown benefits, and our controlled trial showed modest global benefits, but there was also a placebo effect seen. This study focused on a younger age range than the study by Paribello and colleagues ${ }^{22}$ and provides important evidence for the safety on minocycline in the 3.5-15.5 year age range of children with FXS over a three month period. Most adverse events were mild and no severe adverse events occurred with minocycline treatment. However, a concerning long-term side effect of minocycline is graying of the permanent teeth and this study did not last long enough to assess this in patients who have not had eruption of permanent teeth. It is likely that most will have graying of their permanent teeth and caregivers should be counseled about this. It does not appear that gender, baseline IQ, severity of autism spectrum disorder associated behavior as measured on the ADOS, concomitant medication use or methylation status are associated with benefits seen with minocycline treatment.

This study is important because minocycline is a targeted treatment for FXS that is currently available by prescription, whereas other targeted treatments for FXS including the mGluR5 negative modulators are not. Minocycline has numerous biological effects aside from its effects of MMP9 and has been studied as a neuroprotective agent in diseases such as Huntington's disease and multiple sclerosis ${ }^{35,36}$. There are several mechanisms by which minocycline has been theorized to exert its neuroprotective effects including antiinflammatory effects by inhibiting microglial activation, decreasing caspase activity and through antiapoptotic properties ${ }^{19,37}$ (See Figure 2). It is unclear whether these additional neurobiological effects may be beneficial for those with FXS and whether the positive outcome reported here is due to changes in MMP9 levels or additional mechanisms which require further study.

Study limitations include the short treatment period of only three months, as the effects of minocycline may take longer to reach full effect. There was no formal wash out period in the design of the study as there were three months in between the two treatment arms, and it was felt that this would be enough time for the minocycline to be metabolized from the 
participant's system. Carryover effects are therefore possible because the synaptic structural effects of minocycline may persist; this is one limitation of the study. However, the half-life of minocycline is only 15.5 hours and we did not observe a statistically significant carryover effect. It is still unknown whether and how long minocycline may exert beneficial effects once it is discontinued. Minocycline dosing was weight-based, but for optimal effects in FXS, the dosage may have been too low. Longer trials are needed to address long term benefits and side effects. We did not observe significant improvement with minocycline treatment over placebo on any of the secondary measures which may have provided a better indication regarding specific areas of functioning that were responsive to the treatment. An important weakness of the study design is that subjects were unblinded at the time that they completed the study as opposed to the conclusion of the study. This was done for the benefit of the families who wanted to continue on minocycline treatment if it was beneficial to the child. Furthermore, a preliminary efficacy analysis based on subjects who have completed the study was performed showing potential efficacy. These two aspects pose potential bias to the final reported efficacy results. Another weakness is that drug-related side effects have the potential to unblind both subjects and investigators; for minocycline, these include teeth graying and photosensitivity, however there was no significant difference in these effects or any other side effects between the two study groups. We had only one episode of unblinding due to a serious adverse event (a seizure) and the patient was on placebo. A similar number of patients completed the trial in each arm (Figure 1). Finally, the designed study power was $85 \%$. This was not fully achieved potentially since the number of enrolled patients was about $10 \%$ below planned recruitment and not all subjects completed both study periods.

\section{Conclusions}

Minocycline treatment for three months in children with FXS was associated with greater benefits in global functioning when compared with placebo, although the clinical improvement was modest. Treatment with minocycline for three months was safe as almost all side effects were mild and no different than on placebo. Further studies including long term follow up of individuals with FXS treated with minocycline are warranted with a careful assessment of effects on dentition and the immune system.

\section{Acknowledgments}

The authors would like to thank Erika Bickel BS, for her assistance in data collection and Smiley Hom PharmD for his assistance and advice in the study medication preparation process. Ms. Bickel and Dr. Hom have not received any compensation for their contributions. We thank all of the patients and their families whose participation made this study possible.

Funding: We thank the National Fragile X Foundation for their funding of this project. This study was also partially supported by grant UL1 TR000002 from the National Center for Advancing Translational Sciences (DVN), Interdisciplinary Training for Autism Researchers 5T32MH073124 (MJL), A Toolbox of Outcome Measures for Targeted Treatment Trials in Children 3UL1 RR024146-04S4, and the Fragile X Research Center grant HD02274. The funders had no role in study design, data collection and analysis, decision to publish, or preparation of the manuscript.

\section{REFERENCES}

1. Crawford DC, Meadows KL, Newman JL, et al. Prevalence of the fragile X syndrome in AfricanAmericans. Am J Med Genet. 2002; 110:226-233. [PubMed: 12116230]

2. Hagerman PJ. The fragile X prevalence paradox. J Med Genet. 2008; 45:498-499. [PubMed: 18413371]

3. Qin M, Kang J, Burlin TV, Jiang C, Smith CB. Postadolescent changes in regional cerebral protein synthesis: an in vivo study in the FMR1 null mouse. J Neurosci. 2005; 25:5087-5095. [PubMed: 15901791] 
4. Darnell JC, VanDriesche SJ, Zhang C, et al. FMRP stalls ribosomal translocation on mRNAs linked to synaptic function and autism. Cell. 2011; 146:247-261. [PubMed: 21784246]

5. DeRubeis S, Bagni C. Fragile X mental retardation protein control of neuronal mRNA metabolism: Insights into mRNA stability. Mol Cell Neurosci. 2010; 43:43-50. [PubMed: 19837168]

6. Hoeffer CA, Sanchez E, Hagerman RJ, et al. Altered mTOR signaling and enhanced CYFIP2 expression levels in subjects with fragile X syndrome. Genes Brain Behav. 2012; 11:332-341. [PubMed: 22268788]

7. Dolen G, Carpenter RL, Ocain TD, Bear MF. Mechanism-based approaches to treating fragile X. Pharmacol Ther. 2010; 127:78-93. [PubMed: 20303363]

8. Hagerman R, Lauterborn J, Au J, Berry-Kravis E. Fragile X syndrome and targeted treatment trials. Results Probl Cell Differ. 2012; 54:297-335. [PubMed: 22009360]

9. Berry-Kravis E, Hessl D, Coffey S, et al. A pilot open label, single dose trial of fenobam in adults with fragile X syndrome. J Med Genet. 2009; 46:266-271. [PubMed: 19126569]

10. Jacquemont $S$, Curie A, des Portes V, et al. Epigenetic modification of the FMR1 gene in fragile $X$ syndrome is associated with differential response to the mGluR5 antagonist AFQ056. Sci Transl Med. 2011; 3:64ra1.

11. Berry-Kravis E, Sumis A, Hervey C, et al. Open-label treatment trial of lithium to target the underlying defect in fragile X syndrome. J Dev Behav Pediatr. 2008; 29:293-302. [PubMed: 18698192]

12. Berry-Kravis EM, Hessl D, Rathmell B, et al. Effects of STX209 (arbaclofen) on neurobehavioral function in children and adults with fragile $\mathrm{X}$ syndrome: a randomized, controlled, phase 2 trial. Sci Transl Med. 2012; 4:152ra127.

13. Bilousova TV, Dansie L, Ngo M, et al. Minocycline promotes dendritic spine maturation and improves behavioural performance in the fragile X mouse model. J Med Genet. 2009; 46:94-102. [PubMed: 18835858]

14. Sternlicht MD, Werb Z. How matrix metalloproteinases regulate cell behavior. Annu Rev Cell Dev Biol. 2001; 17:463-516. [PubMed: 11687497]

15. Michaluk P, Wawrzyniak M, Alot P, et al. Influence of matrix metalloproteinase MMP-9 on dendritic spine morphology. J Cell Sci. 2011; 124:3369-3380. [PubMed: 21896646]

16. Yrjanheikki J, Tikka T, Keinanen R, et al. A tetracycline derivative, minocycline, reduces inflammation and protects against focal cerebral ischemia with a wide therapeutic window. Proc Natl Acad Sci U S A. 1999; 96:13496-13500. [PubMed: 10557349]

17. Siller SS, Broadie K. Neural circuit architecture defects in a Drosophila model of Fragile X syndrome are alleviated by minocycline treatment and genetic removal of matrix metalloproteinase. Dis Model Mech. 2011; 4:673-685. [PubMed: 21669931]

18. Rotschafer SE, Trujillo MS, Dansie LE, et al. Minocycline treatment reverses ultrasonic vocalization production deficit in a mouse model of Fragile X Syndrome. Brain Res. 2012; 1439:7-14. [PubMed: 22265702]

19. Plane JM, Shen Y, Pleasure DE, et al. Prospects for minocycline neuroprotection. Arch Neurol. 2010; 67:1442-1448. [PubMed: 20697034]

20. Smith K, Leyden JJ. Safety of doxycycline and minocycline: a systematic review. Clin Ther. 2005; 27:1329-1342. [PubMed: 16291409]

21. Utari A, Chonchaiya W, Rivera SM, et al. Side effects of minocycline treatment in patients with fragile X syndrome and exploration of outcome measures. Am J Intellect Dev Disabil. 2010; 115:433-443. [PubMed: 20687826]

22. Paribello C, Tao L, Folino A, et al. Open-label add-on treatment trial of minocycline in fragile $\mathrm{X}$ syndrome. BMC Neurol. 2010; 10:91. [PubMed: 20937127]

23. Roid, GH. Stanford Binet Intelligence Scales. 5th Ed. Riverside Publishing Co.; Rolling Meadows: 2003.

24. Wechsler, D. Wechsler Abbreviated Scale of Intelligence (WASI). Harcourt Assessment, Inc.; San Antonio: 1999.

25. Mullen, EM. Mullen Scales of Early Learning. American Guidance Service; Circle Pines: 1995. 
26. Flemmer DD, Roid GH. Nonverbal intellectual assessment of Hispanic and speech-impaired adolescents. Psychol Rep. 1997; 80:1115-1122. [PubMed: 9246879]

27. Facco E, Zanette G, Favero L, et al. Toward the validation of visual analogue scale for anxiety. Anesth Prog. 2011; 58:8-13. [PubMed: 21410359]

28. de Boer AG, van Lanschot JJ, Stalmeier PF, et al. Is a single-item visual analogue scale as valid, reliable and responsive as multi-item scales in measuring quality of life? Qual Life Res. 2004; 13:311-320. [PubMed: 15085903]

29. Di Benedetto M, Lindner H, Hare DL, et al. A Cardiac Depression Visual Analogue Scale for the brief and rapid assessment of depression following acute coronary syndromes. J Psychosom Res. 2005; 59:223-229. [PubMed: 16223625]

30. Aman MG, Burrow WH, Wolford PL. The Aberrant Behavior Checklist-Community: factor validity and effect of subject variables for adults in group homes. Am J Ment Retard. 1995; 100:283-292. [PubMed: 8554775]

31. Sansone SM, Widaman KF, Hall SS, et al. Psychometric study of the aberrant behavior checklist in fragile X syndrome and implications for targeted treatment. J Autism Dev Disord. 2012; 42:13771392. [PubMed: 21972117]

32. Williams, KT. Expressive Vocabulary Test. American Guidance Service; Circle Pines: 1997.

33. Sparrow, SS.; Cicchetti, DV.; Balla, DA. Vineland Adaptive Behavior Scales. Second Edition. American Guidance Service; Circle Pines: 2005.

34. Tassone F, Pan R, Amiri K, et al. A rapid polymerase chain reaction-based screening method for identification of all expanded alleles of the fragile X (FMR1) gene in newborn and high-risk populations. J Mol Diagn. 2008; 10:43-49. [PubMed: 18165273]

35. Bonelli RM, Heuberger C, Reisecker F. Minocycline for Huntington's disease: an open label study. Neurology. 2003; 60:883-884. [PubMed: 12629257]

36. Metz LM, Li D, Traboulsee A, et al. Glatiramer acetate in combination with minocycline in patients with relapsing--remitting multiple sclerosis: results of a Canadian, multicenter, doubleblind, placebo-controlled trial. Mult Scler. 2009; 15:1183-1194. [PubMed: 19776092]

37. Stirling DP, Koochesfahani KM, Steeves JD, et al. Minocycline as a neuroprotective agent. Neuroscientist. 2005; 11:308-322. [PubMed: 16061518] 


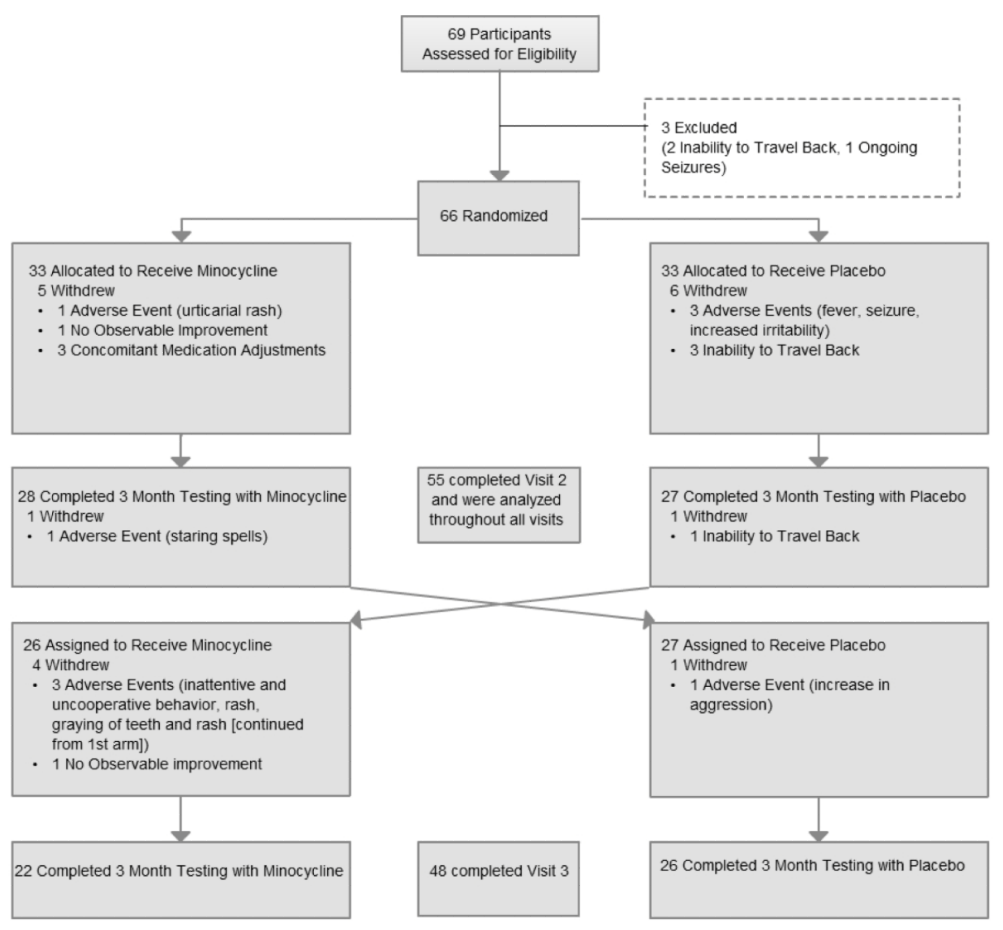

Fig 1.

J Dev Behav Pediatr. Author manuscript; available in PMC 2014 April 01. 


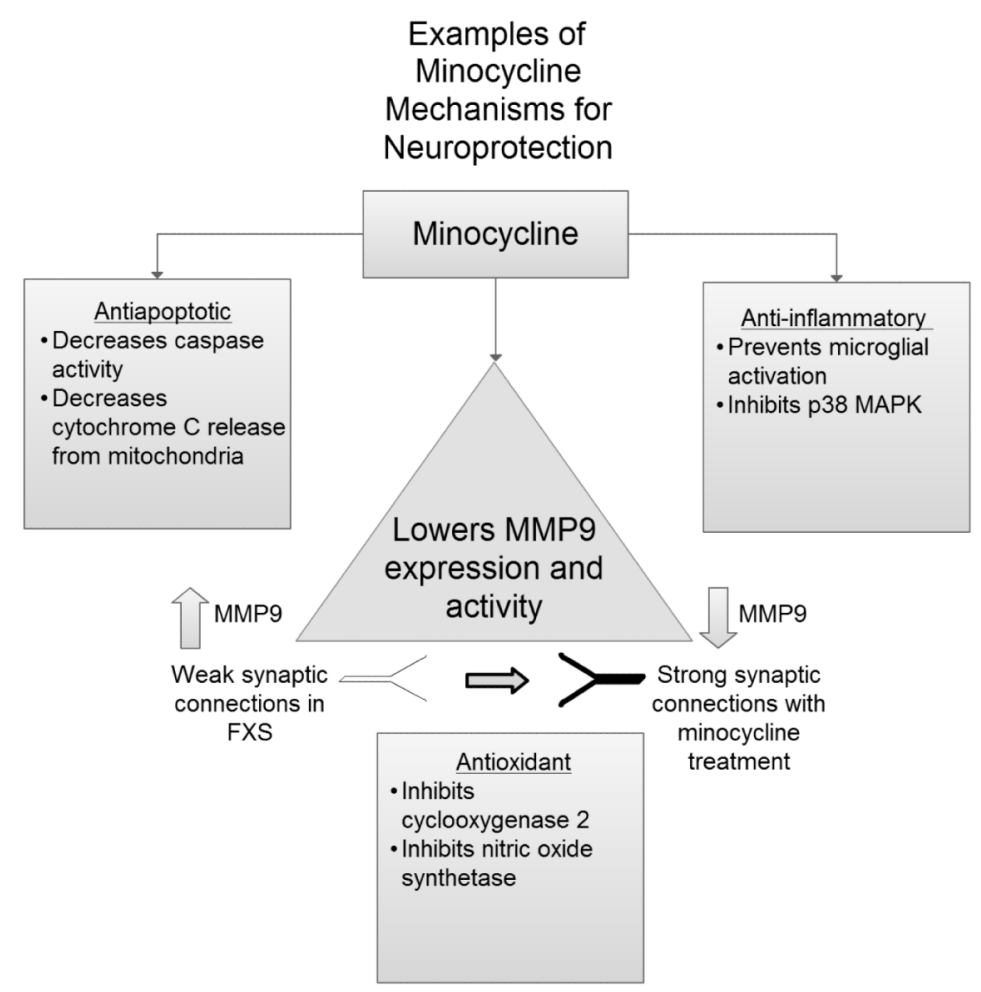

Fig 2. 
Table 1

Demographics

\begin{tabular}{|c|c|c|c|c|c|c|c|}
\hline & \multicolumn{2}{|c|}{ Minocycline-Placebo } & \multicolumn{3}{|c|}{ Placebo-Minocycline } & \\
\hline & N & Mean & SD & N & Mean & SD & P-value \\
\hline Age & 28 & 9.01 & 3.76 & 27 & 9.40 & 3.39 & 0.69 \\
\hline Full Scale IQ Standard Score & 20 & 58.75 & 20.72 & 21 & 52.24 & 11.03 & 0.22 \\
\hline ADOS Total Score & 28 & 9.86 & 5.58 & 27 & 9.67 & 5.41 & 0.90 \\
\hline Age group & N & Percent & & N & Percent & & \\
\hline Age <8yr & 13 & 46 & & 11 & 41 & & 0.79 \\
\hline Age>=8yr & 15 & 54 & & 16 & 59 & & \\
\hline Gender & & & & & & & \\
\hline Female & 5 & 18 & & 3 & 11 & & 0.70 \\
\hline Male & 23 & 82 & & 24 & 89 & & \\
\hline Race & & & & & & & \\
\hline Asian & 2 & 7 & & 4 & 15 & & 0.88 \\
\hline Black/ African American & 1 & 4 & & 1 & 4 & & \\
\hline White & 23 & 82 & & 20 & 74 & & \\
\hline Other & 2 & 7 & & 2 & 7 & & \\
\hline Concomitant Medication & & & & & & & \\
\hline No & 7 & 25 & & 11 & 41 & & 0.26 \\
\hline Yes & 21 & 75 & & 16 & 59 & & \\
\hline Methylation & & & & & & & \\
\hline Full & & 39 & & 7 & 33 & & \\
\hline Partial & & & & & & \\
\hline & & & & & & & \\
\hline & & & & & & & \\
\hline
\end{tabular}


Table 2

Primary Outcome Measures and Ad-Hoc VAS Analysis

\begin{tabular}{|c|c|c|c|c|c|c|c|c|}
\hline & \multicolumn{3}{|c|}{ Baseline } & \multicolumn{2}{|c|}{ Minocycline } & \multicolumn{2}{|c|}{ Placebo } & \multirow[t]{2}{*}{ P-value } \\
\hline & $\mathbf{N}$ & Mean & SE & LSmean 1 & SE & LSmean & SE & \\
\hline 1.Clincal Global Impression-- Improvement Scale * & 55 & -- & -- & 2.49 & 0.13 & 2.97 & 0.13 & 0.02 \\
\hline \multicolumn{9}{|l|}{ 2a. VAS Categorized by Severity } \\
\hline Visual Analog: Severity of Target Behavior $1 *$ & 55 & 2.28 & 0.21 & 4.60 & 0.31 & 4.44 & 0.30 & 0.67 \\
\hline Visual Analog: Severity of Target Behavior 2 & 55 & 2.62 & 0.23 & 4.91 & 0.31 & 4.16 & 0.29 & 0.06 \\
\hline Visual Analog: Severity of Target Behavior 3 & 50 & 2.80 & 0.27 & 4.88 & 0.36 & 4.13 & 0.35 & 0.10 \\
\hline 2b. VAS Categorized by Behavior (Ad-Hoc) & \multicolumn{3}{|c|}{ Baseline } & \multicolumn{2}{|c|}{ Minocycline } & \multicolumn{2}{|c|}{ Placebo } & P-value \\
\hline VAS Behavior Category & $\mathrm{N}$ & Mean & SE & LSmean & SE & LSmean & SE & \\
\hline Aggression/ ADHD & 46 & 2.38 & 0.20 & 4.49 & 0.32 & 4.26 & 0.32 & 0.53 \\
\hline Anxiety/Mood & 26 & 2.47 & 0.25 & 5.26 & 0.46 & 4.05 & 0.46 & 0.05 \\
\hline Language/ Cognition & 37 & 2.58 & 0.30 & 4.99 & 0.37 & 4.67 & 0.34 & 0.51 \\
\hline Other & 12 & 3.49 & 0.66 & 5.84 & 0.54 & 3.41 & 0.54 & 0.009 \\
\hline
\end{tabular}

${ }^{1}$ Least squares mean

(Primary outcome measures, adjusted significance level is 0.025 ) 
Table 3

Characteristics of adverse events (AEs) during minocycline and placebo periods

\begin{tabular}{|c|c|c|c|c|c|c|}
\hline & \multirow[b]{2}{*}{ Category } & \multicolumn{2}{|c|}{ Minocycline } & \multicolumn{2}{|c|}{ Placebo } & \multirow[b]{2}{*}{ P-value } \\
\hline & & $\mathrm{N}$ & $\%$ & $\mathrm{~N}$ & $\%$ & \\
\hline \multirow[t]{3}{*}{ Intensity } & Mild & 67 & 94 & 69 & 95 & 0.63 \\
\hline & Moderate & 4 & 6 & 3 & 4 & \\
\hline & Severe & 0 & 0 & 1 & 1 & \\
\hline \multirow[t]{3}{*}{ Drug related } & Probably related & 2 & 3 & 0 & 0 & 0.93 \\
\hline & Possibly related & 66 & 93 & 66 & 90 & \\
\hline & Not related & 3 & 4 & 7 & 10 & \\
\hline \multirow[t]{2}{*}{ Resolved } & No & 5 & 7 & 1 & 1 & 0.14 \\
\hline & Yes & 66 & 93 & 72 & 99 & \\
\hline \multirow{24}{*}{$\begin{array}{c}\text { Adverse Event } \\
\text { Type } \\
\end{array}$} & Category & & & & & 0.38 \\
\hline & Diarrhea/Loose stools & 15 & 21 & 15 & 21 & \\
\hline & GI upset/Vomiting/Loss of appetite & 9 & 13 & 15 & 21 & \\
\hline & Skin Rash/Itching/Swelling & 12 & 17 & 7 & 10 & \\
\hline & Fever/Chills/URI symptoms/Sore throat & 6 & 8 & 11 & 15 & \\
\hline & Ear infection & 0 & 0 & 2 & 3 & \\
\hline & Fungal skin infection & 1 & 1 & 1 & 1 & \\
\hline & Headache & 4 & 6 & 5 & 7 & \\
\hline & Sunburn/Sun sensitivity & 4 & 6 & 1 & 1 & \\
\hline & Drowsiness & 2 & 3 & 3 & 4 & \\
\hline & $\begin{array}{l}\text { Increased agitation, aggression, } \\
\text { tantrums, uncooperative, irritability }\end{array}$ & 1 & 1 & 4 & 5 & \\
\hline & $\begin{array}{l}\text { Blue-grey/Grey hue to teeth or other } \\
\text { tissues }\end{array}$ & 3 & 4 & 1 & 1 & \\
\hline & Yellowish teeth & 3 & 4 & 0 & 0 & \\
\hline & Brownish teeth & 2 & 3 & 0 & 0 & \\
\hline & Dark colored urine/Changes in urination & 1 & 1 & 2 & 3 & \\
\hline & Increased appetite & 2 & 3 & 1 & 1 & \\
\hline & Trouble sleeping & 2 & 3 & 0 & 0 & \\
\hline & Seizure/Staring spell & 1 & 1 & 1 & 1 & \\
\hline & Dizziness/Unsteadiness & 0 & 0 & 1 & 1 & \\
\hline & Masturbation & 1 & 1 & 0 & 0 & \\
\hline & Right leg pain & 1 & 1 & 0 & 0 & \\
\hline & Constipation & 1 & 1 & 1 & 1 & \\
\hline & Sneezing, itchy eyes & 0 & 0 & 1 & 1 & \\
\hline & PE tubes removed & 0 & 0 & 1 & 1 & \\
\hline
\end{tabular}

